\title{
A two-dimensional particle tracking model for pollution dispersion in A Coruña and Vigo Rias (NW Spain)
}

\author{
Moncho GOMEZ-GESTEIRA a , Pedro MONTERO a , Ricardo PREGO $^{\text {b }}$, Juan José TABOADA a \\ Paulo LEITAO ${ }^{c}$, Manuel RUIZ-VILLARREAL ${ }^{a}$, Ramiro NEVES ${ }^{c}$,Vicente PEREZ-VILLAR ${ }^{a}$ \\ ${ }^{a}$ Group of Nonlinear Physics, Faculty of Physics, 15706 Santiago de Compostela, Spain. uscfmrgg @ cesga.es \\ ${ }^{\mathrm{b}}$ Instituto de Investigaciones Marinas, CSIC, Vigo, Spain \\ ${ }^{c}$ Departamento de Engenharia Mecânica, Instituto Superio Técnico (IST), Lisboa, Portugal
}

(Received 21 January 1998, revised 24 March 1998, accepted 24 June 1998)

\begin{abstract}
A two-dimensional hydrodynamic model coupled to a particle tracking model is applied to study the dispersion processes and residence time in two Galician rias (A Coruña and Vigo, NW Spain) under summer conditions. In A Coruña a long residence time was found in the harbour area due to the existence of a dock, and a short one in the river area. On the contrary, in Vigo, the residence time is smaller in the harbour area, due to the Rande Strait, beyond which the river effect is negligible. (C) Elsevier, Paris / Ifremer / Cnrs / Ird
\end{abstract}

two-dimensional model / passive tracers / residual currents / pollution / Galician rias

Résumé - Modèle bidimensionnel de suivi des particules et dispersion de la pollution dans les rias de La Corogne et de Vigo (Espagne). Un modèle hydrodynamique bidimensionel couplé à un modèle de suivi des particules a été appliqué à deux rias de Galice (La Corogne et Vigo) pour étudier la dispersion et les temps de résidence dans les deux estuaires en été. Dans la ria de La Corogne, le temps de résidence des eaux est important dans la zone portuaire et court à l'embouchure du fleuve. L'inverse est observé dans la ria de Vigo, où le détroit de Rande limite l'effet du fleuve. (O Elsevier, Paris / Ifremer / Cnrs / Ird

modèle bidimensionnel / traceur passif / circulation résiduelle / pollution / rias de Galice

\section{INTRODUCTION}

According to the classic definition of F. von Richtofen [31], a ria is a transverse coast, resulting from a marine transgression, which interferes with a preexistent relief of fluvial origin [37]. Along the northwestern shoreline of the Iberian Peninsula [26], a great number of bays correspond to this general description.

The vertically integrated two-dimensional (2D) models have been widely used over the last two decades $[1,11$, $16,24,33]$. In spite of the improvement of three-dimensional (3D) models during the past decade, 2D models still remain valid to describe situations with a weak verti- cal stratification. They are very useful for wave phenomena such as tides and tidal currents, or transport of solutes for which effective dispersion coefficients can be determined empirically. Thus, a 2D model can be used to describe the above-mentioned rias, during seasons with low river discharge or when the area under study is far enough from the river mouth, and stratification is weak. Finally, one of the main advantages of 2D models is their low computational cost. Some of the Galician rias have been studied by different authors using these kinds of models. Pascual $[28,29]$ modelled the circulation driven by tide and wind in the Ria de Arousa. Using a finite-element method, Bermúdez et al. [5, 6], carried out different numerical studies in the rias of Pontevedra and Vigo. 
Montero et al. [20] analyzed the dispersion of pollutants near Vigo harbour using a finite-differences Eulerian method.

Our aim throughout this paper is to describe how hydrodynamics can control the water quality in the A Coruña and Vigo Rias. The analysis will be based on the dispersion of passive traces (particle tracking model), which simulate the transport of a generic contaminant dumped into the estuary. Results will be related to the residual velocity field - defined as the velocity averaged in each point during a period much longer than the period of the main tidal harmonics. A lagrangian model constitutes a powerful tool for studying dispersion in estuaries. It allows analysis of dispersion and estimation of residence times at a low computational cost compared to eulerian models. This gives the conclusions of this study an applicability only found in some preliminary results $[15,22]$. In particular, we will consider the least favourable conditions in terms of residence time: summer conditions with small river discharge and negligible wind stress.

\section{STUDY AREAS}

The Ria of A Coruña (figure la) belongs to the so-called Galician Rias Altas. Its main axis is $6 \mathrm{~km}$ long and its mouth is about $3 \mathrm{~km}$ wide. The inner zone of the Ria which includes the harbour area - has estuarine features while the outer zone is under oceanic influence. The River Mero mean annual discharge is $6 \mathrm{~m}^{3} \mathrm{~s}^{-1}$. Due to these features, some authors [36] have claimed that, from a hydrological point of view, A Coruña is not a ria but a bay. Their argument is corroborated by the mean estuarine Richardson number: $R \cong 0.03$, smaller than the upper limit for well-mixed estuaries $(R=0.08)$ and one order of magnitude above that for stratified estuaries $(R=0.8)$. The mean estuarine Richardson number $[13,14]$ is defincd as $R i_{E}=g \frac{\Delta \rho}{\rho} \frac{Q_{f}}{b U_{t}^{3}}$, where $\mathrm{Q}_{\mathrm{f}}$ is the river discharge, $b$ the mean width of the estuary, $\Delta \rho$ is the density difference between river water entering at the head of the estuary and sea water at the mouth and $\rho$ is the mean density; $g$ is the acceleration due to gravity and $U_{t}$ is the $r m s$ of the tidal velocity.

The ria of Vigo (figure $1 b$ ) is the southernmost of the socalled Galician Rias Baixas. Its main axis is $33 \mathrm{~km}$ long and the whole estuary can be divided into three different areas. The innermost area corresponds to the San Simon inlet. It has estuarine features due to the tidal effect and the River Oitaben outflow (about $13 \mathrm{~m}^{3} \mathrm{~s}^{-1}$ ). The middle part stretches from the Strait of Rande to the Cape of Mar. The outermost zone, downstream of Cape of Mar to the Cies Islands, is under oceanic influence.

In the ria of Vigo, the mean estuarine Richardson number is $R \cong 0.08$. Actually, during the wet season, the estuary behaves as partially mixed displaying a two-layered rcsidual current pattern due to the high river discharge. On the other hand, during the dry season, the river flow is low and, in absence of upwelling and intense heat radiation, the ria of Vigo behaves as a weakly stratified estuary $[23,30]$.

Despite both estuaries being quite different from a hydrological point of view (see table $I$ ), they share common management needs. The biggest human settlements in Galicia are the cities of A Coruña and Vigo (250000 inhabitants each) and the two most important Galician harbours are located in these estuaries - the oil refinery located in A Coruña has provoked several accidents with considerable oil spills over recent decades. The control of water quality alone justifies the estimation of the renovation rate of the whole estuary - or of particular areas.

Table I. Physical and computational characteristics of A Coruña and Vigo Rias.

\begin{tabular}{lcc}
\hline & A Coruna & Vigo \\
\hline Volume & $251 \mathrm{hm}^{3}$ & $3275 \mathrm{hm}^{3}$ \\
Mean Width & $3.1 \mathrm{~km}$ & $4.8 \mathrm{~km}$ \\
Mean Depth & $16 \mathrm{~m}$ & $21 \mathrm{~m}$ \\
Main Axis Length & $5 \mathrm{~km}$ & $32.5 \mathrm{~km}$ \\
Mean River Flow & $6 \mathrm{~m}^{3} \mathrm{~s}^{-1}$ & $13 \mathrm{~m}^{3} \mathrm{~s}^{-1}$ \\
Computational Time Step & $25 \mathrm{~s}$ & $25 \mathrm{~s}$ \\
Computational Grid Mesh & $50 \mathrm{~m}$ & $200 \mathrm{~m}$ \\
Grid Size & $103 \times 114$ & $162 \times 116$ \\
Turbulent Diffusion Coefficient & $50 \mathrm{~m}^{2} \mathrm{~s}^{-1}$ & $50 \mathrm{~m}^{2} \mathrm{~s}^{-1}$ \\
Drag Coefficient & $0.022 \mathrm{~m}^{1 / 3} \mathrm{~s}^{-1}$ & $0.022 \mathrm{~m}^{1 / 3} \mathrm{~s}^{-1}$ \\
Imposed River Flow & $3 \mathrm{~m}^{3} \mathrm{~s}^{-1}$ & $3 \mathrm{~m}^{3} \mathrm{~s}^{-1}$ \\
\hline
\end{tabular}

\section{MODEL}

In order to investigate the transport processes under summer conditions (i.e. low river flow and negligible wind stress) a 2D model was considered. This barotropic model is coupled to a particle tracking model $[7-9,12$, 19]. The hydrodynamics model, MOHID (MOdelo HIDrodinâmico) [24] solves the continuity and momentum conservation equations: 


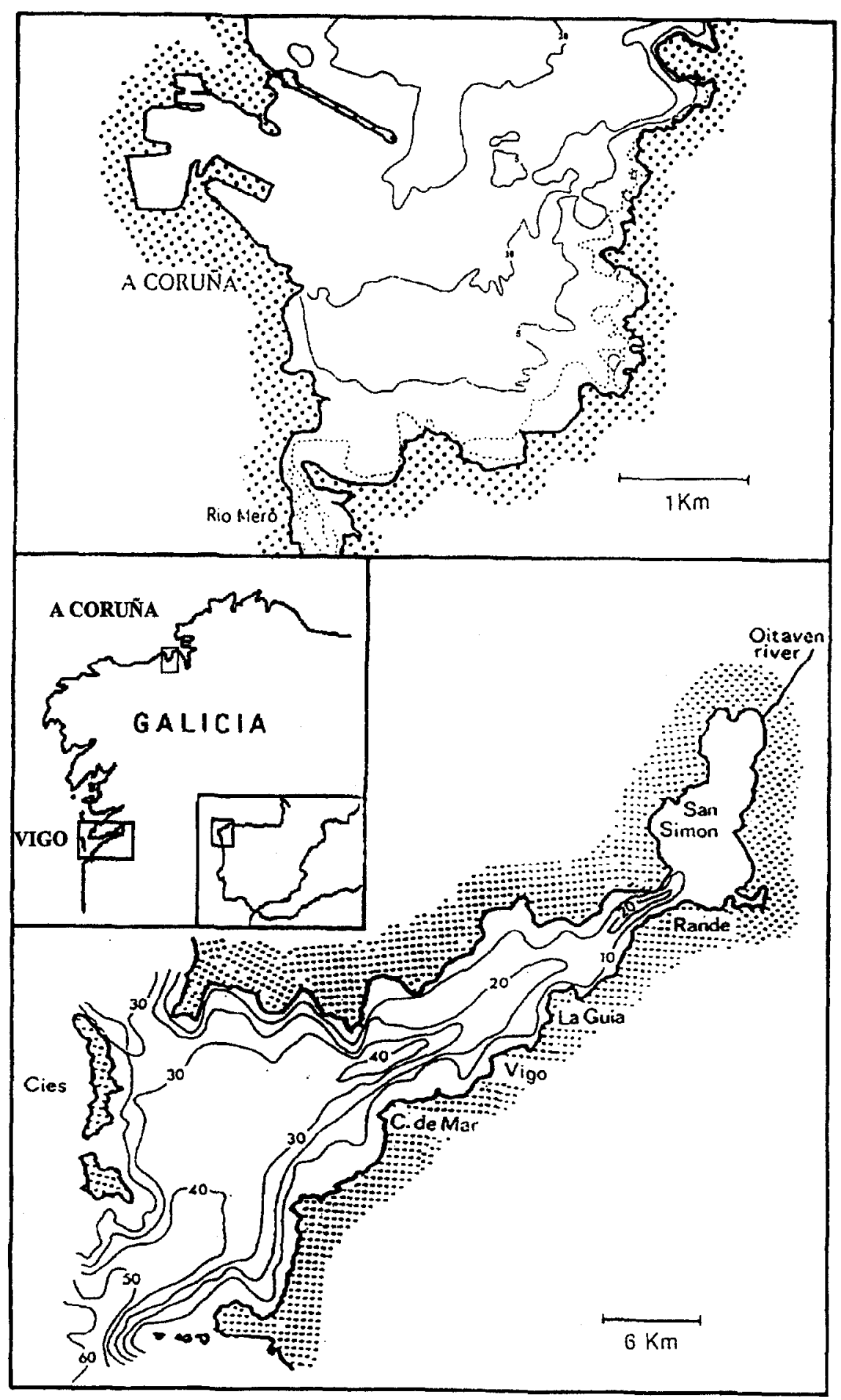

Figure 1. (a) Bay of A Coruña. (b) Ria of Vigo. 


$$
\begin{aligned}
& \frac{\partial \zeta}{\partial t}+\frac{\partial(H u)}{\partial x}+\frac{\partial(H v)}{\partial y}=0 \\
& \frac{\partial(H u)}{\partial t}+\frac{\partial(H u u)}{\partial x}+\frac{\partial(H u v)}{\partial y}-H f v \\
& =-H g \frac{\partial \zeta}{\partial x}-\left(\tau_{h x}-\tau_{s x}\right)+H v\left(\frac{\partial^{2} u}{\partial x^{2}}+\frac{\partial^{2} u}{\partial^{2}}\right) \\
& \frac{\partial(H v)}{\partial t}+\frac{\partial(H u v)}{\partial x}+\frac{\partial(H v v)}{\partial y}+H f u \\
& =-H g \frac{\partial \zeta}{\partial y}-\left(\tau_{h y}-\tau_{s y}\right)+H v\left(\frac{\partial^{2} v}{\partial x^{2}}+\frac{\partial^{2} v}{\partial y^{2}}\right)
\end{aligned}
$$

where $(u, v)$ are the vertically integrated velocity components, $(x, y)$ the Cartesian coordinates, $\zeta$ the elevation over a reference level, $t$ the time, $H$ the water column height, $f$ the Coriolis parameter (twice the vertical component of the Earth's rotation vector), $g$ the gravity acceleration, (the turbulent horizontal viscosity, and $\tau_{b i}$ and $\tau_{s i}$ the bottom and wind shear stresses in the $\mathrm{i}$ direction.

In this set of equations the hydrostatic hypothesis and the Boussinesq approximation have been assumed. Besides, the Coriolis parameter has been considered to be constant, since the size of the area under study is small.

To solve this set of equations numerically, MOHID uses an Arakawa- $\mathrm{C}$ grid [3] with a semi-implicit alternating direction scheme. A $1 D$ model was coupled to the $2 \mathrm{D}$ model to simulate the river flow. Experimentally measured river discharges $[30,36]$ were imposed at the most inland grid point of the 1D model. The turbulent viscosity is considered to be constant in time and space (see table $I$ for values). At open ocean boundaries the elevation over the reference level was imposed by means of the tidal harmonics provided by the Instituto Hidrográfico de la Marina (the amplitude of the main tidal harmonic M2 is 1.09). Along the solid boundaries, a null normal velocity was imposed and a free slip condition was assumed, since the grid is not fine enough to simulate the horizontal boundary layers.

The bottom stress was calculated using a quadratic law and a constant Manning rugosity $\left(0.022 \mathrm{~m}^{1 / 3} \mathrm{~s}^{-1}\right)$. No wind stress was considered because in estuaries like A Coruña and Vigo, the wind has little effect on the residual current pattern. The initial conditions were a horizontal level and null velocity. The hydrodynamic model was run during an initialization period of one day to adjust the solution to the periodic circulation regime. During this period, the time step and the turbulent diffusion coefficient were progressively adapted to their stationary value.

The eulerian residual current is calculated integrating the solution calculated at every time step by the hydrodynamic model $\left(u_{M}\right): u_{R}=\frac{1}{T} \int_{0}^{T} u_{M} d t$, where $T$ is the integration period, much longer than the tidal period.

As mentioned above, a particle tracking model (PARTIC) [25] was coupled to the hydrodynamic model to describe the movement of passive tracers. The main advantage of a fully lagrangian formulation over eulerian transport models [2, 9] is its higher accuracy in describing localized emission spots avoiding artificial numerical diffusion in presence of sharp gradients. Besides, the method provides considerable time saving, because it only follows the track of the locally dumped particles, in contrast with eulerian transport models, which calculate the concentration of any property anywhere in the simulation domain.

The particle tracking model assumes that the velocity of each particle $\left(\mathrm{u}_{\mathrm{p}}\right)$ can be split into a large-scale organized flow, characterized by a mean velocity $\left(u_{M}\right)$, provided by the hydrodynamic model, and a smaller scale random fluctuation $\left(\mathrm{u}_{\mathrm{F}}\right)$ such that $u_{P}=u_{M}+u_{r^{*}}$

Following [8] it is possible to prove that the lagrangian method is equivalent to solving the transport equation for a certain property.

$\frac{\partial q}{\partial t}+u_{M_{i}} \frac{\partial q}{\partial x_{i}}=A_{i j} \frac{\partial^{2} q}{\partial x_{i} \partial x_{j}}$

where $A_{i j}$ is the dispersion coefficient matrix. Normally in 2D dispersion study cases, shear effect dispersion is not considered leading to $A_{11}=A_{22}=A$ and $A_{12}=A_{21}=0$, which avoids a lot of numerical problems in the eulerian approach. Considering the random velocity with a top hat distribution, then $u_{F} \in[-p, p]$, where $p$ can be related to the dispersion coefficient as:

$A=\frac{p^{2} \Delta t}{6} \Leftrightarrow p=\sqrt{\frac{6 A}{\Delta t}}$

where $\Delta t$ is the time step. Usually, (4) and (5) are solved after an analysis of the relevant scales in the phenomenon under study following Ozmidov [27].

Leitao [18] made a sensibility analysis to test the relative importance of the three main dispersion processes in a 
well-mixed estuary: advection, horizontal turbulent diffusion and shear effect dispersion. The last effect was simulated imposing a velocity profile on a $2 \mathrm{D}$ hydrodynamic model. One of the main conclusions of this work was that advection is the main process and the other phenomena play minor roles. Thus, when studying big areas (the whole estuary) over several tidal cycles it is possible to neglect shear effect and to consider a main advective term and a small random fluctuation (horizontal turbulent diffusion). In summary, in the estuaries under study and considering a grid mesh of about $100 \mathrm{~m}$ and a time step of $25 \mathrm{~s}$, it is formally correct to consider a random fluctuation in tracer velocities, since it only affects slightly the transportative properties.

The used particle-tracking model computes the equation

$\frac{d X}{d t}=U(X, t)$

at each time step. $X=X(x, y)$ is the tracer position at $\mathrm{t}$ and $U(X, t)$ the tracer velocity. The previous equation is solved by a simple explicit method. $U(X, t)$ has a mean component $\left(u_{M}\right.$, advective transport) that is calculated at each $X$ position by linear interpolation of the velocity field provided by the hydrodynamic model, and a random component ( $u_{F}$, turbulent transport).

Following [34] and [2], the tracer random velocities are simulated using a mixing length $(L)$ and the root mean square of turbulent velocity $\left(u_{\sigma}\right)$. This is an excellent methodology to simulate the shear effect dispersion in well-mixed flows where an analytical profile velocity can be imposed [2], and also in 3D cases, whenever the 3D model is coupled with a 1D turbulence model [18]. The objective of Allen's methodology is to model the physics of the dispersion process in a more realistic way than the standard diffusion equation. In our case, this methodology was extended to calculate horizontal turbulent diffusion.

The mixing length in this methodology represents the tracer displacement from which a new random velocity is computed. Formally, we can affirm that it represents the distance to which correlation between turbulent velocity and tracer displacement tends to zero $\left.\left(u_{F} X\right) \rightarrow 0\right)$, [35]. A turbulent velocity with a top hat distribution was considered in this work, while Allen [2] used a simple discrete distribution $u_{F}= \pm u_{\sigma}$.

To extend Allen's methodology to our case, it is necessary to define a characteristic dimension $L$, which can be assumed to be the dimension of the biggest eddies not resolved by the hydrodynamic model, in other words, the horizontal mixing length. Theoretically, this dimension is equal to twice the grid mesh [4]. Allen's methodology also needs values of turbulent diffusion standard deviation. These values can be determined using in situ measurements, although they were not available in the present study. Nevertheless, the following relation was admitted,

$\frac{u_{\sigma_{1}}}{\sqrt{u_{M_{1}}^{2}+u_{M_{2}}^{2}}}=\frac{u_{\sigma_{2}}}{\sqrt{u_{M_{1}}^{2}+u_{M_{2}}^{2}}}=0.2$

which is consistent with averaged field data in other estuaries with similar characteristics [10]. The turbulent velocity of each tracer $\left(u_{F}\right)$ was computed using the equation,

$$
\begin{aligned}
& u_{F}=\operatorname{Rand} \times \sqrt{3} \times u_{\sigma} \\
& =\operatorname{Rand} \times \sqrt{3} \times 0.2 \times \sqrt{u_{M_{1}}^{2}+u_{M_{2}}^{2}}
\end{aligned}
$$

where Rand is a random function with a top hat distribution between -1 and 1 .

The velocity $u_{F}$ is recalculated after a time $\left(\Delta t_{L}\right)$, which does not necessarily coincide with the hydrodynamic model time step.

$\Delta t_{L}=\frac{L}{u_{\sigma}}=\frac{2 \times \Delta x}{0.2 \times \sqrt{u_{M_{1}}^{2}+u_{M_{2}}^{2}}}$

where $\Delta x$ is the grid mesh. Formally, $u_{F}$ should be used in (9) instead of $u_{\sigma}$, but the probability of $u_{F}$ having very low values in relation to $L$ is very high and, consequently, there is also a great probability of having high $\Delta t_{L}$ values. In the limit, if $u_{F}$ is small enough, a tracer can maintain the same turbulent velocity during several tidal cycles. In summary, $\Delta t_{L}$ does not represent the time a tracer needs to perform a random step, but the average time the tracer needs to perform the random step.

Special attention should be paid to describing tracer movement near the boundaries. Particles can move from the $2 \mathrm{D}$ to the $1 \mathrm{D}$ domain and vice-versa. When they move from the $1 \mathrm{D}$ into the $2 \mathrm{D}$, they are placed randomly along the interface. The particles that move out of the computational domain through the open boundary are assumed to loose their identity and do not return. Finally, those particles crossing the solid boundary are relocated at their previous position. 
In both estuaries particles were emitted from two boxes. The first box was placed near the river mouth and the second one close to the harbour area. This particular choice is due to the fact that those areas are the most polluted oncs in both cstuarics.

\section{RESULTS AND DISCUSSION}

Figure 2 shows the residual flow field in the ria of $\mathrm{A}$ Coruña. The flow pattern is due both to the interaction between tidal forcing and bathimetry features (mainly the dock), and to the river discharge [32]. It is possible to observe the existence of three small eddies close to the river mouth (counter clockwise, clockwise and counter clockwise respectively from west to east). In the northern area, near the dock, there are two bigger eddies, which are situated to the north and south of the dock and rotate counter clockwise and clockwise respectively.

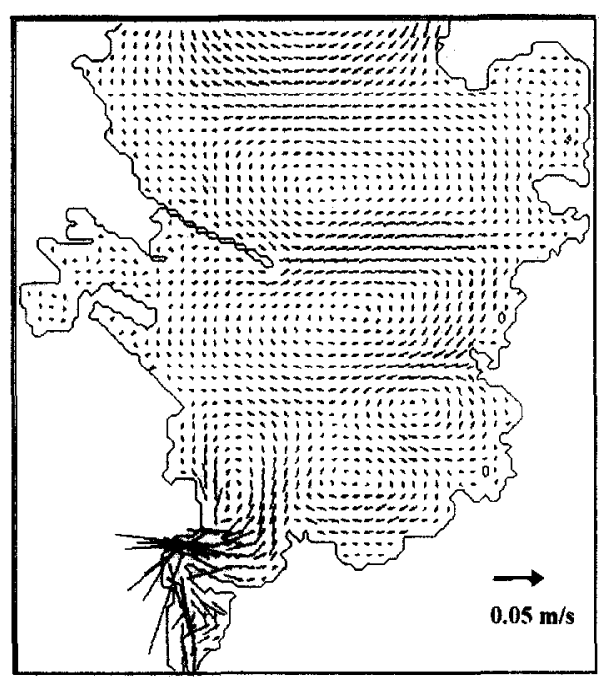

Figure 2. Residual current calculated in A Coruña over 28 days.

Other features can be observed in this general circulation pattern. Inside the harbour the residual current is negligible while in the southernmost area higher values, due to the shallowness of the channel more than to the high river flow, are observed.

The displacement of the particles emitted from the boxes (figure 3) confirms some of the features glimpsed through the residual current analysis. Most of the particles emitted in the harbour (darker colour particles in figure $3 a$ ) remain there throughout the calculation. Only some of them, initially placed in the outermost area of the harbour, are able to move out under the influence of the eastward jet generated by the northernmost eddies (figure $3 b$ ). Once these particles arrive at the eastern coast, they spread northwards and southwards due to both eddies (figure $3 c$ ). Finally, only a small percentage of the particles initially placed inside the harbour were able to leave it. Among these particles, only some of them drift out of the estuary, and the remainder drift to the inner part of the estuary (figure $3 d$ ).

On the other hand, the particles initially placed near the river mouth (lighter colour in figure $3 a$ ), leave that area rapidly (figure $3 b$ ). Nevertheless, there is no jet transporting the particles outward, they spread along the southernmost part of the estuary (figures $3 c, 3 d$ ) due to the existence of the three eddies mentioned above. Besides, once the particles attain the main eddy (located southern of the dock) they follow a pathway similar to that followed by the particles situated in the outermost part of the harbour. Experimental measurements [36] display low salinity values near the dock, which seems to confirm our predictions of the river water pathway.

The probability of the dumped particles leaving their initial boxes after 14 days is shown in figure 4 . For a particle initially placed in the harbour area the probability is 0.3 . Only the particles initially placed at the outermost part of the harbour will have left the zone during the first week (as shown in figure 3). The particles leave the river area much faster. The probability is 0.8 after five days and almost 1 after 14 days.

In the ria of Vigo the situation is quite different. The residual flow pattern is much more complex (figure 5), which is mainly due to the complexity of the bathimetry. In the outermost part of the ria (near the Cies Islands), there is a large eddy rotating counter clockwise. All along the ria, there are plenty of small eddies produced by the shoreline (they appear even in absence of river foreing), which consists of irregular shaped shallow basins. The area beyond the Rande Strait (San Simon Bay) presents a very complex circulation pattern with high residual velocities due to the shallowness of the area. Nevertheless, the direction of the current (inwards or outwards) through the strait cannot be directly deduced from the residual current. 

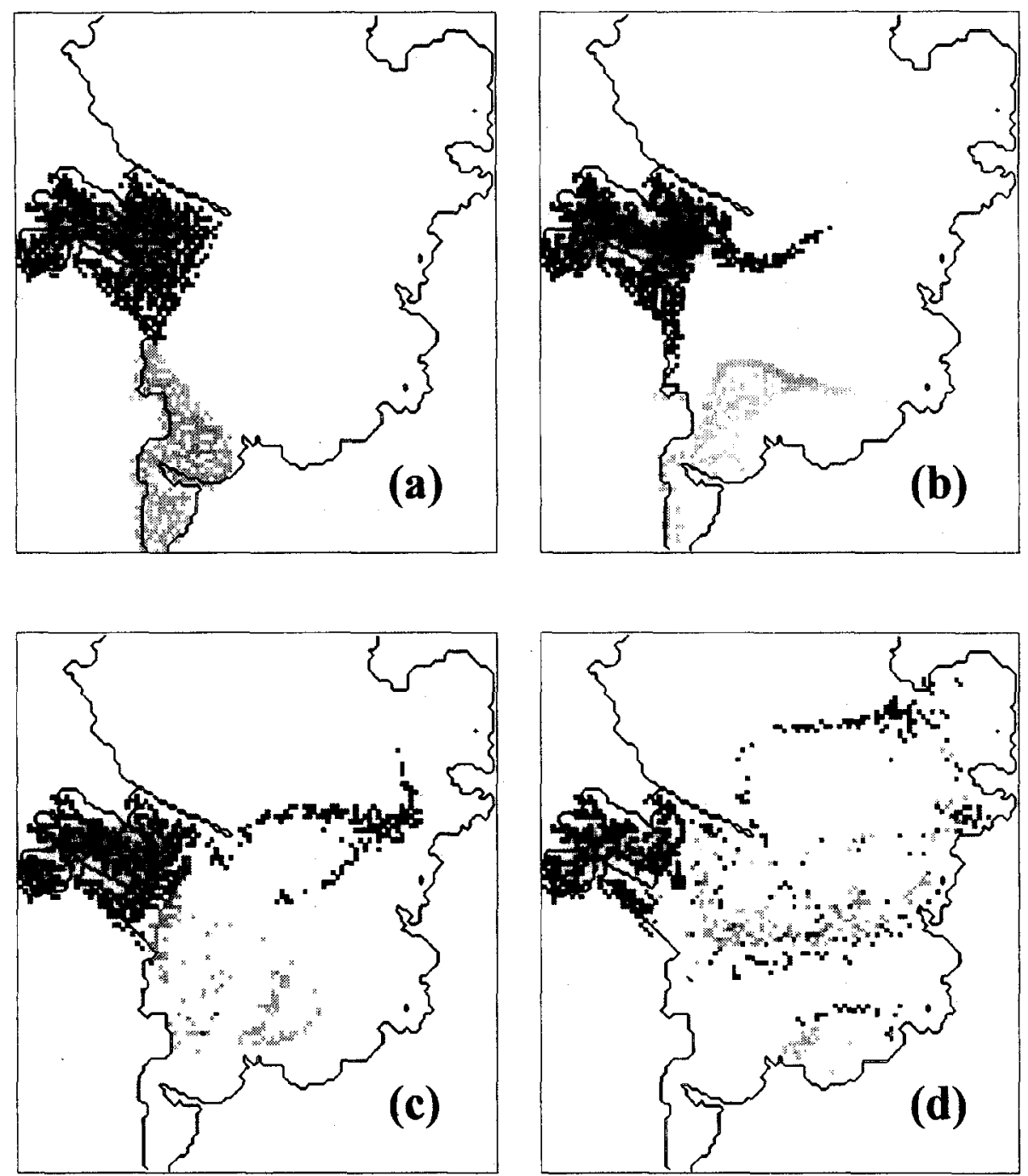

Figure 3. Particle tracking result in A Coruña Bay at (a) beginning of the calculation, where the particles in the river area are represented in a lighter colour, and particles in the harbour area are represented in darker colour, (b) 5th day, (c) 11 th day and (d) 14th day.

Once again, the emission boxes (figure 6) can provide additional information that helps to clarify conclusions obtained analyzing the residual flow. A considerable percentage of the particles initially placed in the harbour area (lighter coloured particles in figure $6 a$ ) leave it during the first week (figure $6 b$ ). These particles spread inwards and outwards (figures $6 c, 6 d$ ) due to the existence of the small eddies mentioned above. The particles initially placed in the river area (San Simon Bay) (darker colour in figure 6a), start leaving the area during the two first weeks (figures $6 b, 6 c$ ), but they tend to accumulate in the Rande Strait afterwards (figure $6 d$ ).

Figure 7 provides some additional information, which may highlight that given in figure 6 . After the first week a particle will have left the harbour area with a probability of almost 0.5. During the following weeks, particles continue to leave the arca very slowly, in fact, the probability barely increases. A similar behaviour is observed near the river area, during the first two weeks the probability 


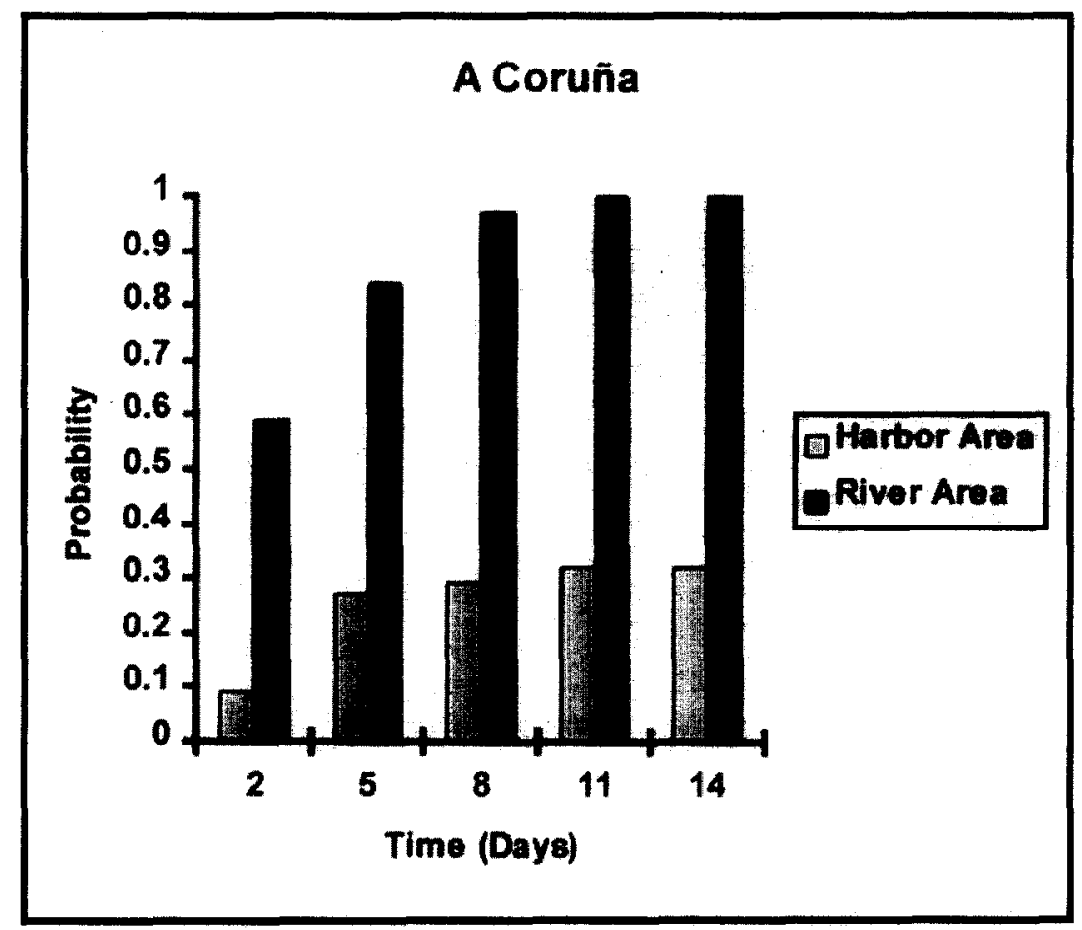

Figure 4. Probability of a particle leaving. the area (harbour or river) where initially placed in A Coruña Bay.

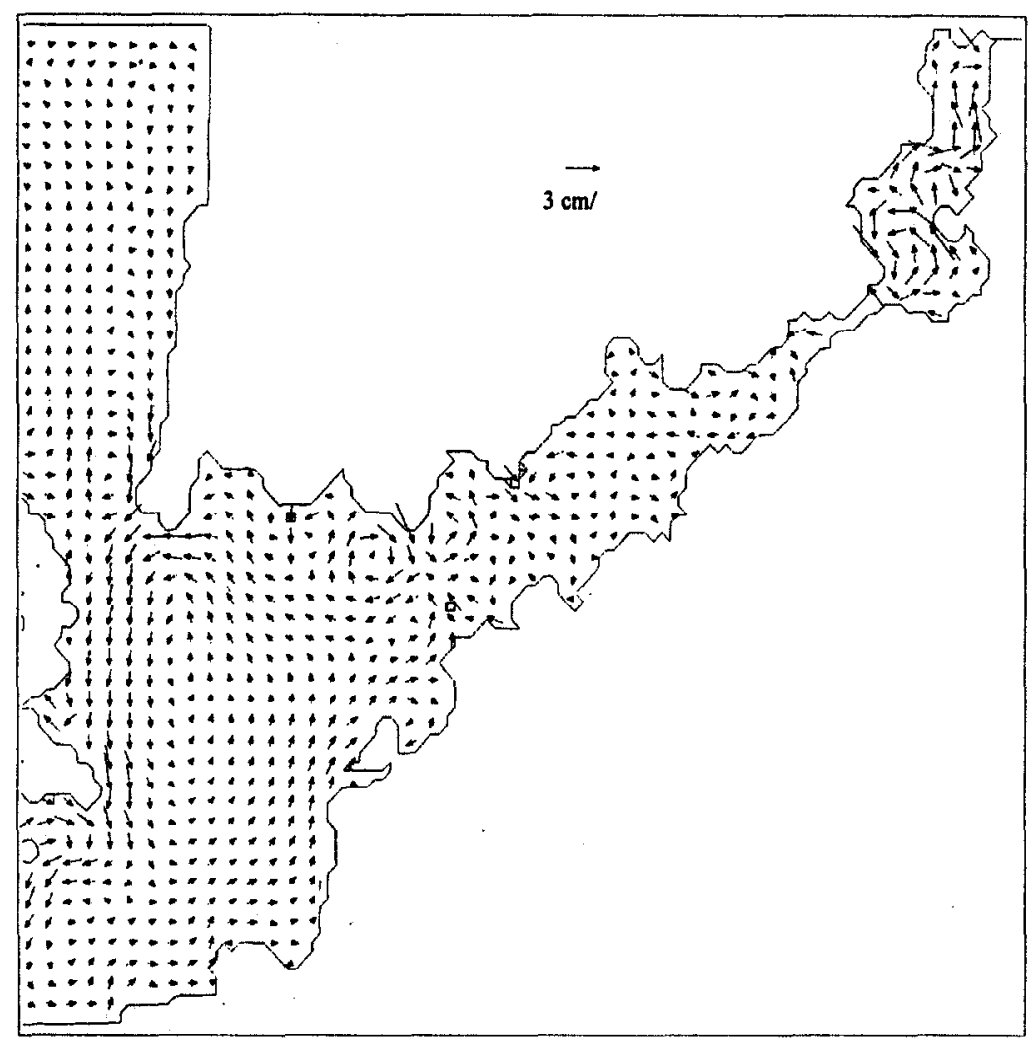

Figure 5. Residual current calculated in Vigo Ria during 28 days. 

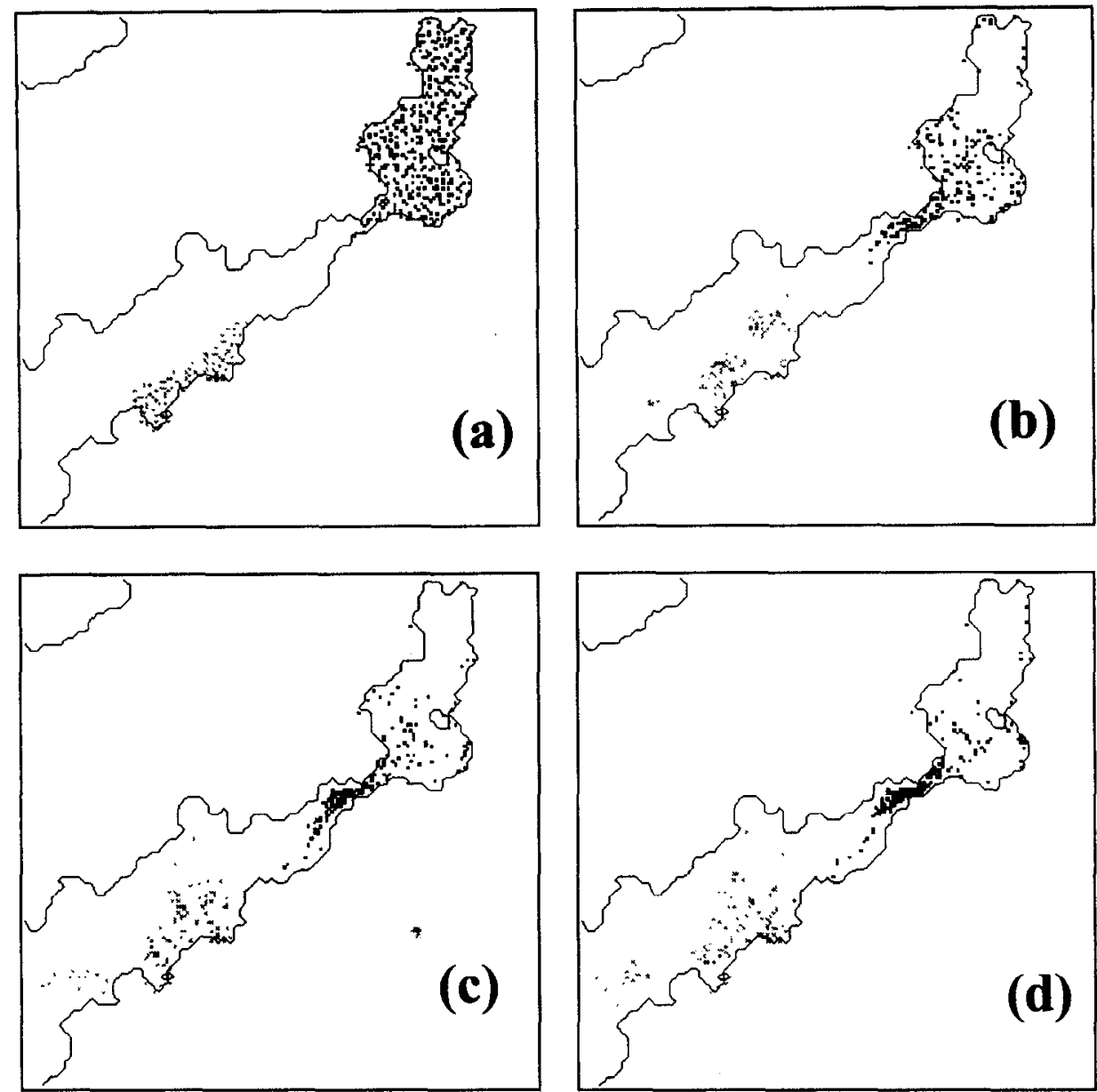

Figure 6. Particle tracking result in Vigo Ria at (a) beginning of the calculation, where the particles in the harbour area are represented in a lighter colour, and particles in the river area are represented in darker colour, (b) 7th day, (c) 14th day and (d) 21 st day.

grows to 0.2 , but it stabilizes around that value for the rest of the calculation.

\section{CONCLUSIONS}

A 2D barotropic model coupled to a particle tracking model was used to investigate contaminant dispersion in two Galician rias. This study was carried out under low river discharge conditions, corresponding to the longest residence time. Under these conditions, estuaries are well mixed and a 2D model can be used accurately.

A passive tracer can be assigned to a water mass transporting any contaminant released in that water mass. In this way, the probability of a given tracer to remain in the area where it was initially placed is related to the residence time of the water in that area.

In $\mathrm{A}$ Coruña $\mathrm{Ria}$, where the oceanic influence is strong in every season, the river area showed a short residence time (in eight days the probability of a particle remaining in the area is negligible). On the contrary, the harbour area had a long residence time. Actually, most of the particles in the innermost part of the harbour hardly moved out. This is due to the presence of a dock, which affects the circulation of the southernmost zone of the estuary.

The ria of Vigo has three different zones as mentioned above, the harbour area showed a residence time shorter than the one corresponding to A Coruña, but the particles coming from the river tend to accumulate around the Rande Strait despite the existence of strong tidal currents in that area. This is due to the low river discharge and to 


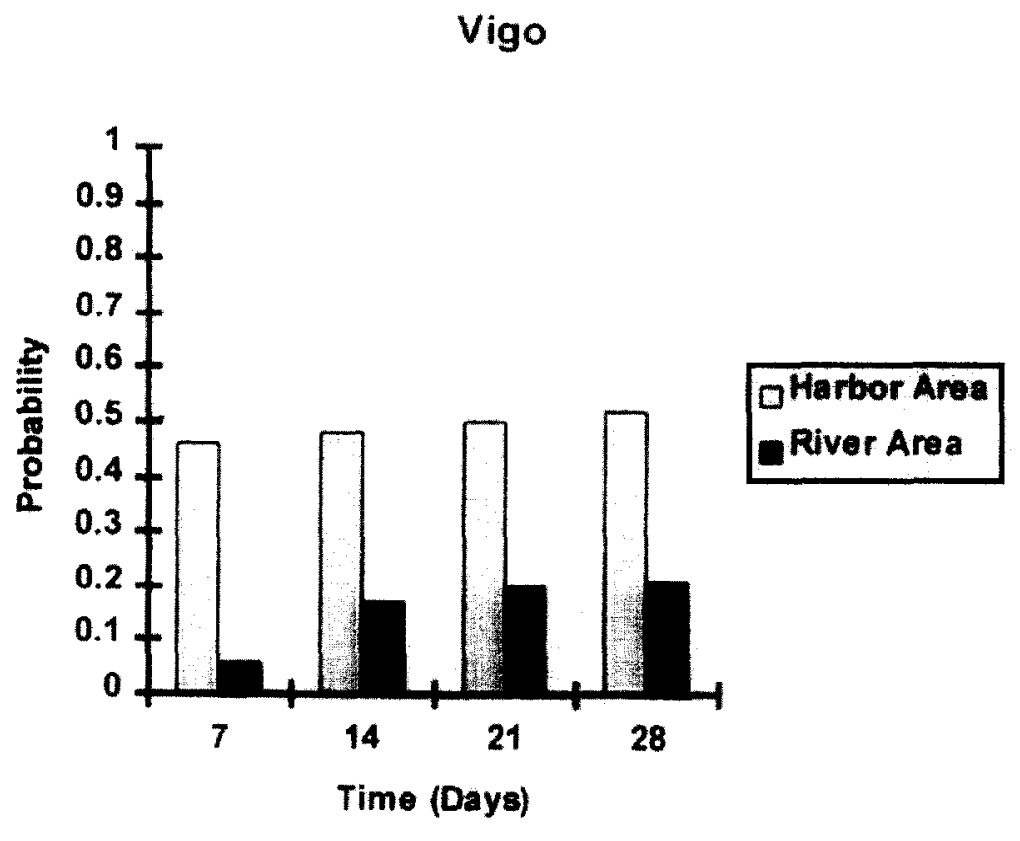

Figure 7. Probability of a particle leaving the area (harbour or river) where initially placed in Vigo Ria.

the narrowness of the Rande Strait, which avoids the creation of large gyres in the area. The situation would be completely different under winter conditions, since the high river flow induces the appearance of more complex two layer dynamics as reported both experimentally [30] and numerically in a preliminary 3D study by Montero et al. [21].

In summary, the presented particle tracking model has proved to be a powerful tool for studying dispersion phe- nomena. It allows the residence time in the estuaries to be estimated, which can be used to analyze water quality, at a low computational cost.

\section{Acknowledgments}

One of us (P.M.) is indebted to HIDROMOD S.L. team for his inestimable help during his stay in Lisbon.

\section{REFERENCES}

[1] Abbott M.B., Damsgaard A., Rodenhuis G.S., System 21, Jupiter, A design system for two-dimensional nearly-horizontal flows, J. Hyd. Res. 1 (1973) 1-28.

[2] Allen C.M., Numerical simulation of contaminant dispersion in estuary flows, Proc. R. Soc. London. A 381, (1982) 179194.

[3] Arakawa A., Lamb V.R., Computational Design of the basic dynamical processes of the UCLA General Circulation Model, Meth. Comput. Phys. 17 (1977) 174-264.
[4] Bedfore K.W., Diffusion, Dispersion and sub-grid parameterization, Costal, Estuarial and Harbour Engineer's Reference Book, Abbett M.B., Price W.A. (eds.), 1993.

[5] Bermúdez A., Martínez A., Rodriguez C., Un problème de contrôle ponctuel lié à l'emplacement optimal d'émissaires d'évacuation sous-marins, C.R. Acad. Sci. Paris 313 I (1991) 515-518.

[6] Bermúdez A., Rodríguez C., Vilar M.A., A numerical method for resolution of two-dimensional shallow-water equations, Revista de Geociências, Univ. Lisboa-8 (1994) 63-66. 
[7] Book D.L., (ed.) Finite difference techniques for vectorized fluid dynamics calculations, Springer-Verlag, New York, 1981,226 p.

[8] Bork I., Maier-Reimer E., On the spreading of power plant cooling water in tidal river applied to the river Elbe, Adv. in Water Res. 1 (1978) 161-168.

[9] Chu W., Gardner S., A two-dimensional particle tracking estuarine transport model, Water Res. Bull. 22 (1986) 183189.

[10] Darbyshire E.J., West J.R., Turbulence and Cohesive Sediment Transport in the Parrett Estuary, in: Clifford N.J., French J.R., Hardisty J., (Eds.), Turbulence - Perspectives on Flow and Sediment Transport, 1993.

[11] Falconer R.A., A mathematical model study of the flushing characteristic of a shallow tidal bay, Proceedings of the Institution of Civil Engineers, part 277 (1984) 311-322.

[12] Fischer H.B., A Method for Predicting Pollutant Transport in Tidal Waters, Contribution 132, Water Resources Center, Univ. of California (1970).

[13] Fischer H.B., Mass transport mechanisms in partially stratified estuaries, J. Fluid Mech. 53 (1972) 671-687.

[14] Fischer H.B., List E.J., Koh R.C.Y., Imberger J., Brooks N.H., Mixing in inland and coastal waters, Academic Press, London, $1979,483 \mathrm{p}$.

[15] Gómez-Gesteira M., Pérez-Muñuzuri V., Montero P., Souto M.J., Taboada J.J., Pérez-Villar V., From fluid equations to meteorological and oceanographic modeling: Influence of the boundary conditions, Complex systems in natural and economic sciences, ELFT, Budapest, 1996.

[16] Leendertse J.J., Aspects of a computational model for a long period wave propagation, Ph.D. Thesis, Technische Hogeschool te Deldt, Netherlands, 1967, 165 p.

[17] Leitão P., Three-dimensional Lagrangian Dispersion Model, Masters Thesis, Universidade Técnica de Lisboa - Instituto Superior Técnico, 1997.

[18] Leitão P.C., Miranda R., Coelho H.S., Transport and Mixing Simulation along the Continental Shelf Edge Using a Lagrangian Approach, 2nd Symposium on the Atlantic Iberian Continental Margin, Cádiz, 1997, 17-20 September 1997.

[19] Maier-Reimer E., Sünderman J., On tracer methods in computational hydrodynamics, Engineering Applications of Computational Hydraulics I (1982) 198-217.

[20] Montero M., Lloret A., Ruiz-Mateo A., Water renovation rate in Bouzas basins, in: R.A. Falconer et al. (Eds.), Hydraulic and environmental modelling: Coastal Waters, Vol I. 1992, pp. 263-276.

[21] Montero P., Taboada J.J., Gómez- Gesteira M., Prego R., Pérez-Villar V., Modelado 3D de Rias Gallegas, Proceedings de la XXV Reunion Bienal de la Real Sociedad Española de Física, Bravo Quintas R., Salgado J. (Eds.), Carballo, Santiago de Compostela, 1995, pp. 55-56.
[22] Montero P., Prego R., Gómez-Gesteira M., Neves R., Taboada J.J., Pérez-Villar V., Aplicación de un modelo 2D al transporte de partículas en la bahía de la Coruña, in: Procesos Biogeoquimicos en sistemas costeros hispanos lusos, Actas del VIII Seminario Ibérico de Química Marina (1997) 131-136.

[23] Mouriño C., Fraga F., Fernández Pérez F., Hidrografía de la Ria de Vigo, 1979-80. Actas do primeiro seminario de Ciencias do Mar: As rias galegas, Ed. do Castro, A Coruña, 1984, 91-103.

[24] Neves R., Étude expérimentale et modélisation mathématique des circulations transitoire et résiduelle dans l'estuaire du Sado, Ph.D. Thesis, Univ. Liège, Belgique (1985).

[25] Neves R., Ferreira J.N., Remedio J.M., Dos Santos A.J.P., Marine hydrodynamical and biogeochemical models: lagrangian dispersion models and circulation model of the gulf of Cadiz, Water Poll. Res. Report 20 (1990) 39-43.

[26] Noon H., Les régions côtières de la Galice (Espagne), Étude Géomorphologique, Pub. Fac. de Lettres, Univ. Strasbourg, $1966,591 \mathrm{p}$.

[27] Ozmidov R.V., Diffusion of Contaminants in the Ocean, Oceanographic Sciences Library, Kluwer Academic Publishers, $1990,283 \mathrm{p}$.

[28] Pascual J.R., The vertical and horizontal M2 tide in the Ría de Arosa (Galicia, Spain NW), Rev de Geofísica, Univ. Complutense Madrid 43 (1987a) 57-64.

[29] Pascual J.R., Un modelo de circulación inducida por el viento en la Ría de Arosa, Bol. Inst. Esp. Oceanogr. 4 (1987b) 107120.

[30] Prego R., Fraga F., A simple model to calculate the residual flows in a Spanish ria. Hydrographics consequences in the ria of Vigo, Est, Coast. Shelf Sci. 34 (1992) 603-615.

[31] Richthofen von F., F. Forschungsreisende, Jenecke, 1886, $734 \mathrm{p}$.

[32] Robinson I.S., Tidally induced residual flows, in: Johns B. (Ed.), Physical oceanography of coastal and shelf seas, Elsevier, Amsterdam, 1983, pp. 321-356.

[33] Ronday F., Modèles Hydrodynamiques, Projet Mer, Rapport tinal, 1976, 3

[34] Sullivan P.J., Longitudinal dispersion within a two-dimensional turbulent shear flow, J. Fluid Mech. 49 (3) (1971) 551-576.

[35] Tennekes H., Lumley E., A First Course in Turbulence, MIT Press (Eds), 1972.

[36] Varela M., Prego R., Canle M., Lorenzo J., The Ría de La Coruña, is hydrologically a ria? Revista de Geociências, Univ. Lisboa 8 (1994) 3-5.

[37] Vidal Romaní J.R., A orixe das rias galegas: Estado da cuestión (1886-1983), Actas do primeiro seminario de Ciencias do Mar: As rias galegas, do Castro (Ed.), A Coruña, 1984, pp. 13-26. 